\title{
Изучение онлайн вербовки, осуществляемой ИГИЛ, с использованием теории развития отношений
}

\section{Сара Пондер ${ }^{a}$ и Джонатан Матусиц ${ }^{b}$}

а Школа коммуникаций им. Никольсона, Университет Центральной Флориды, https://communication.ucf.edu/

b Школа коммуникаций им. Никольсона, Университет Центральной Флориды, Центр партнерства - Семинол колледж штата Флорида, https://www.seminolestate.edu/s/m/university-partnership-center

Резюме: В этой работе используется теория развития отношений для изучения вопроса о том, как Исламское государство Ирака и аль-Шама (ИГИЛ) вербует новых членов. Теория развития отношений постулирует, что люди следуют определенным этапам отношений для усиления их межличностной коммуникации или социальных связей. Модель развития отношений включает пять основных этапов, называемых этапами эскалации отношений или этапами «схождения». Это инициация, экспериментирование, интенсифицирование, интегрирование и привязывание. В общем и целом, авторы этого анализа пришли к выводу, что ИГИЛ оказывается в состоянии успешно вербовать большое количество людей - в частности, молодых мужчин и женщин - благодаря поэтапному развитию отношений через Интернет чатрумы и такие сайты социальных сетей (ССС), как Твиттер. Точно так же, авторы считают, что если бы ИГИЛ не использовало чатрумы и сайты социальных сетей и, если бы ИГИЛ не следовало этим этапам эскалации отношений, их процесс вербовки не был бы настолько эффективным.

Ключевые слова: халифат, Интернет, ИГИШ, радикализация, развитие отношений, социальные медиа, терроризм, Твиттер. 


\section{Введение}

В этой работе применяется теория развития отношений для изучения вопроса, как Исламское государство Ирака и аль-Шама (ИГИШ) вербует новых членов. ИГИШ является могущественной исламистской террористической организацией, ответственной за совершение большого числа вооруженных нападений на невинные гражданские лица в таких регионах, как Ближний Восток. ИГИШ убеждено, что надо создать халифат (исламскую систему мирового управления). Теория развития отношений основана на постулате, что люди следуют последовательным этапам развития отношений для того, чтобы усилить свои межличностные коммуникации или социальные связи. ${ }^{1}$ Модель развития отношений включает пять основных этапов, называемых пятью этапами эскалации отношений или этапами «схождения». Это инициация, экспериментирование, интенсификация, интеграция и привязывание. ${ }^{2}$ Инициацией является этап, на котором человек устанавливает контакт с другим человеком. Экспериментирование имеет место, когда человек пытается узнать больше о другом человеке и определить, хочет он или нет продолжать эти отношения. Интенсификация происходит, когда люди уже чувствуют себя комфортабельно в межличностном диалоге и начинают делиться личными подробностями. Интегрирование осуществляется, когда люди начинают идентифицировать себя вместе или как часть одной и той же группы. И привязывание есть публичная демонстрация верности и полномасштабной преданности группе.

В общем и целом, авторы данного анализа пришли к выводу, что ИГИШ может успешно вербовать большое количество людей - в частности, молодых мужчин и женщин, - благодаря поэтапному развитию отношений через интернет чатрумы и такие сайты социальных сетей (ССC), как Твиттер. Подобным образом, авторы считают, что если бы ИГИЛ не использовало интернет чатрумы и сайты социальных сетей (ССС) и, если бы ИГИШ не следовало этим этапам эскалации отношений, их процесс вербовки не был бы настолько эффективным. Анализ начинается детальным описанием теории развития отношений (основанным на всех пяти этапах). Затем авторы продолжают описанием ИГИШ и его методов вербовки. Далее следует сущность данного анализа: рассмотрение вербовки, осуществляемой ИГИЛ, через призму теории развития отношений. Анализ завершается обсуждением, включающим рекомендации для будущих исследований.

1 Mark L. Knapp, Social Intercourse: From Greeting to Goodbye (Boston, MA: Allyn and Bacon, 1978); Mark L. Knapp, Interpersonal Communication and Human Relationships (Boston, MA: Allyn and Bacon, 1984).

2 Mark L. Knapp and John A. Daly, eds., Handbook of Interpersonal Communication, 3rd ed. (Thousand Oaks, CA: Sage, 2002). 


\section{Теория развития отношений}

Разработанная Кнаппом, ${ }^{3}$ теория развития отношений объясняет, как взаимодействующие субъекты - т.е. пары, переговорщики и так далее - следуют определенным этапам, чтобы усилить свои межличностные коммуникации или социальные связи. В этой теории полагается, что отношения претерпевают развитие, проходя через определенные этапы в результате межличностного диалога. Этот диалог проливает свет на положительный или отрицательный опыт взаимодействующих субъектов и на модификации их интимности или способов коммуникации. ${ }^{4}$ Теория развития отношений основывается еще на предположении, что «отношения развиваются, проходя через определенные фазы в результате межличностного диалога». ${ }^{5}$ Модель развития отношений включает пять основных этапов эскалации отношений или этапов «схождения». В их число входят инициация, экспериментирование, интенсификация, интеграция и привязывание. ${ }^{6}$ Поскольку эскалация отношений подразумевает циклы совместного вырастания, она не будет работать для отношений, которые находятся в стадии распада. ${ }^{7}$

\section{Инициация}

Когда начинают развивать отношения между собой, незнакомые люди имеют намерения, надежды, потребности, желания и убеждения, которые руководят их действиями. ${ }^{8}$ Первым этапом эскалации отношений или «схождения» является инициация: этап, на котором личность устанавливает контакт с другой личностью. На этом этапе люди замечают друг друга и начинают делиться своими историями. Этот этап является важным, поскольку на нем формируются первые элементы знаний о данной личности, называемые «первым впечатлением». ${ }^{9}$ Концепция первого впечатления имеет существенное воздействие на развитие отношений: она оказывает

3 Knapp, Social Intercourse; Knapp, Interpersonal Communication and Human Relationships.

4 Theodore A. Avtgis, Daniel V. West, and Traci L. Anderson, "Relationship Stages: An Inductive Analysis Identifying Cognitive, Affective, and Behavioral Dimensions of Knapp's Relational Stages Model," Communication Research Reports 15, no. 3 (1998): 280-287.

5 Jonathan Matusitz, Terrorism and Communication: A Critical Introduction (Thousand Oaks, CA: Sage, 2012), цитата на стр. 365.

6 Knapp and John A. Daly, eds., Handbook of Interpersonal Communication.

7 Daniel J. Canary, Michael J. Cody, and Valerie L. Manusov, Interpersonal Communication: A Goals Based Approach, 4th ed. (New York: Bedford/St. Martin's, 2008).

8 Dorothy Miell and Steve Duck, "Strategies in Developing Friendships," in Friendship and Social Interaction, ed. Valerian J. Derlega and Barbara A. Winstead (New York: Springer, 1986), 129-143.

9 Michael Sunnafrank and Artemio Ramirez, Jr., "At First Sight: Persistent Relational Effects of Get-Acquainted Conversations," Journal of Social and Personal Relationships 21, no. 3 (2004): 361-379. 
влияние на мнение о качестве личности, часто определяет дальнейшую судьбу отношений (будут они продолжаться или нет) и остается на долгое время в сознании другого взаимодействующего субъекта - следовательно, чем лучше первое впечатление, тем более положительно будет восприниматься данная личность. Хотя воздействие первого впечатления может быть очень глубоким, оно может сформироваться за долю секунды в зависимости от того, как коммуникирует данная личность, или в зависимости от таких ее внешних и физических характеристик, как его или ее внешний вид, язык тела или одежда. ${ }^{10}$

\section{Экспериментирование}

Согласно Фоксу, Уорберу и Максталлеру, экспериментирование осуществляется, когда кто-то пытается узнать больше о другом и решает продолжать или не продолжать отношения с ним. ${ }^{11}$ Этот этап обычно имеет место сразу после фазы инициации. На фазе экспериментирования люди хотят собрать информацию о другом человеке, задавая вопросы. Они ищут общие интересы, частично раскрывая себя и корригируя возможные ошибки, допущенные при произведении первого впечатления (сформированного на предшествующем этапе инициации). В охват обмениваемой на этом этапе информации входят личные интересы. ${ }^{12}$

Экспериментирование является зондирующим этапом, на котором люди осуществляют дальнейшее оценивание друг друга, что Кнапп называет «попыткой раскрыть неизвестное». ${ }^{13}$ Уелч и Рубин считают, что «коммуникаторы исследуют сходства и в целом расширяют круг тем, редко углубляясь во что-нибудь конкретное». ${ }^{14}$ Общий разговор на этом этапе является весьма информативным, так как он дает взаимодействующим субъектам возможность выявить больше деталей друг о друге и расширить текущий спектр данных отношений. Кнапп указывает на то, что на этом этапе отношения накладывают ограниченные требования на взаимодействующие субъекты. ${ }^{15}$

10 Christopher Y. Olivola and Alexander Todorov, "Elected in 100 milliseconds: Appearance-Based Trait Inferences and Voting," Journal of Nonverbal Behavior 34, no. 2 (2010): 83-110.

11 Jesse Fox, Katie M. Warber, and Dana C. Makstaller, "The Role of Facebook in Romantic Relationship Development: An Exploration of Knapp's Relational Stage Model," Journal of Social and Personal Relationships 30, no. 6 (2013): 771-794.

12 Paul A. Mongeau and Mary Lynn Miller Henningsen, "Stage Theories of Relationship Development: Charting the Course of Interpersonal Communication," in Engaging Theories in Interpersonal Communication: Multiple Perspectives, ed. Leslie A. Baxter and Dawn O. Braithwaite (Thousand Oaks, CA: Sage, 2008), 363-375.

13 Knapp, Social Intercourse, p. 21.

14 S-A Welch and Rebecca B. Rubin, "Development of Relationship Stage Measures," Communication Quarterly 50, no. 1 (2002): 24-40, цитата на стр. 25.

$15 \mathrm{Knapp}$, Interpersonal Communication and Human Relationships. 


\section{Интенсификация}

Интенсификация происходит, когда личности начинают чувствовать себя более комфортабельно при межличностном диалоге. Фокс и др. пришли к выводу, что люди часто раскрывают больше информации на фазе интенсификации; тогда же начинают устанавливаться и межличностные отношения. ${ }^{16}$ На этом этапе статус отношений между личностями можно обозначить как «близкие друзья». Взаимодействие включает более свободное самораскрытие (т.е. раскрытие более персональной информации) и более интимные вербальные и невербальные действия (использование ников и комплиментов), неформальную речь, просьбы об услугах и так далее. ${ }^{17}$ Появляются более прямые выражения привязанности. В двух словах, окончательно формируются межличностные близкие отношения: происходит более глубокое раскрытие и коммуникация подтверждает дружбу, которая уже сложилась. ${ }^{18}$

\section{Интегрирование}

Интегрирование происходит, когда люди начинают идентифицировать себя вместе или как часть одной группы. На этом этапе появляются крепко связанные группы. Здесь можно применять термин «сцепка»: люди начинают выглядеть похоже (невербально) и думают о себе, как о друзьях. ${ }^{19}$ Они близки в смысле настроений, интересов и мнений. Отношения уже являются персональными и устойчивыми: люди часто делятся интимной информацией и секретами, и личности обмениваются определенными аспектами своей социальной идентичности (например, в отношение друзей, семьи и мест обитания). ${ }^{20}$ Люди начинают «носить» идентичность друг друга в виде интимных знаков. Например, через рисунки и заколки, они достигают более высокой синхронизации поведения. ${ }^{21}$

\section{Привязывание}

Этап Привязывания осуществляется, когда люди начинают публично идентифицировать себя с определенной личностью или группой. На этом этапе

16 Fox, Warber, and Makstaller, "The Role of Facebook in Romantic Relationship Development."

17 Denise Haunani Solomon and Anita L. Vangelisti, "Relationship Development," in Interpersonal Communication, ed. Charles R. Berger (Berlin: De Gruyter Mouton, 2014), 347-369.

18 Knapp, Social Intercourse: From Greeting to Goodbye.

19 Welch and Rubin, "Development of Relationship Stage Measures."

20 Darius K.-S. Chan and Grand H.-L. Cheng, "A Comparison of Offline and Online Friendship Qualities at Different Stages of Relationship Development," Journal of Social and Personal Relationships 21, no. 3 (2004): 305-320.

21 Richard Moniz, Jo Henry, and Joe Eshleman, Fundamentals for the Academic Liaison (Chicago: American Library Association, 2014). 
близкие отношения выражаются в официальном, публичном признании данных отношений или аффилиации - например, в форме официальных обещаний, церемонии или ритуала, - и в самой высокой степени эмпатии, доверия и близости. ${ }^{22}$

\section{Исламское государство Ирака и аль-Шама (ИГИШ)}

Иногда называемое в СМИ Исламским государством Ирака и Леванта (ИГИЛ), или просто Исламским государством, Исламское государство Ирака и аль-Шама (ИГИШ) является экстремистской мусульманской террористической организаций, которая контролирует обширные территории Ирака и Сирии, а также меньшие области в таких африканских странах, как Ливии и Нигерия. ИГИШ так же активно присутствует в других частях света, включая Юго-восточную Азию. ${ }^{23}$ Корни ИГИШ восходят к Аль-Каиде в Ираке (АКИ), террористической группировке, основанной Абу Мусаб аль-Заркави, иорданским воинствующим исламистом. В 2006 году, когда Заркави был уничтожен силами США и Ирака, новым лидером стал Абу Аюб аль-Масри, египтянин, подхвативший дело так называемого тогда Исламского государства Ирака (ИГИ). В 2010 году Абу-Бакр аль-Багдади был провозглашен новым халифом - после убийства Масри (бывшего лидера), также силами США и Ирака. В апреле 2013 аль-Багдади переименовал организацию на Исламское государство Ирака и аль-Шама. ${ }^{24}$

ИГИШ свято верит в установление халифата. Халифат - это мировое исламское государство, некая исламская система управления всем миром. ${ }^{25}$ Движение за создание халифата пытается (1) восстановить правление халифа (верховного религиозного и политического лидера ислама); (2) установить шариат (кодекс исламского права, проистекающий из Корана и хадисов) которому должны подчиняться как умма (сообщество правоверных мусульман), так и не-мусульмане во всем мире; (3) в итоге распространить исламскую доктрину над всем миром. ${ }^{26}$ Чтобы осуществить создание халифата, ИГИШ заявляет, что оно призвано аллахом совершать широкомасштабные, скоординированные нападения, как против мусульман, так и про-

22 Mark L. Knapp and Anita L. Vangelisti, Interpersonal Communication and Human Relationships, 6th ed. (Boston, MA: Pearson Education, 2008).

23 Jay Sekulow, Jordan Sekulow, Robert W. Ash, and David French, Rise of ISIS: A Threat We Can't Ignore (Brentwood, TN: Howard Books, 2015); Ishaan Tharoor, "ISIS or ISIL? The Debate over What to Call Iraq's Terror Group," The Washington Post, June 18, 2014, p. A1.

24 Zana Khasraw Gulmohamad, "The Rise and Fall of the Islamic State of Iraq and Al-Sham (Levant) ISIS," Global Security Studies 5, no. 2 (2014): 10-21.

25 Futoshi Matsumoto, "The World Order and a New "Behemoth"," Asia-Pacific Review 22, no. 1 (2015): 177-190.

26 Guy Rodgers, Understanding the Threat of Radical Islam (Broomall, PA: National Highlights, 2012). 
тив не-мусульман. Террористические действия включают взрывы смертников, взрывы машин, массовые экзекуции, пытки и обезглавливание. Терроризм ИГИШ часто демонстрируется публично. Это и есть конечная цель терроризма: запугать население, чтобы оно оказывало поддержку или, по крайней мере, не оказывало сопротивление. Захват ИГИШ города Мосул (в северном Ираке) 10 июня 2014 года является доказательством пугающей военной силы этой организации. ${ }^{27}$ Город Мосул начали считать воплощением халифата ИГИШ или Исламского государства.

\section{Вербовка, осуществляемая ИГИШ}

Сегодня ИГИШ является одной из наиболее быстро растущих, наиболее склонных к использованию насилия и наиболее богатых террористических организаций в мире. ${ }^{28}$ ИГИШ твердо верит в создание халифата и ведет джихад во имя аллаха. Как формулируют это Вейс и Хасан, «ИГИШ уничтожило границы современных национальных государств и провозгласило себя восстановителем утерянной исламской империи». ${ }^{29}$ ИГИШ в значительной степени опирается на свою кампанию стратегической коммуникации. Лидеры ИГИШ доказали превосходное владение использованием онлайн социальных медиа для вербовки и пропаганды, которые критически важны для успеха и роста этой организации. Они очень квалифицированы в овладении вниманием Западного мира: через онлайн видеоклипы они пропагандируют ужасные картины и жестокость как в умме (сообщество правоверных мусульман), так и в не-мусульманском мире. ${ }^{30}$ Хотя многие рассматривают эту жестокость как гротеск, но она, к сожалению, дает представление о беспрецедентном могуществе, которым располагает ИГИш. ${ }^{31}$

27 Stansfield, "The Islamic State, the Kurdistan Region and the Future of Iraq: Assessing UK Policy Options," International Affairs 90, no. 6 (2014): 1329-1350.

28 Seongju Oh, Chaeyun Jung, and Taeseon Yoon, "Analysis of the Development of IS (Islamic State) in Its Relation to Conflicts within OIC (Organization of Islam Countries) by Using SPSS Statistical Program," International Journal of Social Science and Humanity 6, no. 10 (2016): 799-804.

29 Michael Weiss and Hassan Hassan, ISIS: Inside the Army of Terror (New York: Regan Arts, 2015), цитата на с. 8.

30 C. Akça Ataç, "A Comparative Civilizational Reading for the Middle East and Turkey's New Role in It," Global Change, Peace \& Security 28, no. 1 (2016): 99-115.

31 Daveed Gartenstein-Ross, "Testimony to the Committee on Homeland Security and Governmental Affairs, United States Senate," in Jihad 2.0: Social Media in the Next Evolution of Terrorist Recruitment, S. Hrg. 114-438 (Washington, D.C.: U.S. Government Publishing Office, 2016), 12-21, https://www.hsdl.org/?abstract\&did= 798565. 


\section{игиш и сайты социальных сетей (CCC)}

Есть три главных нарратива, которые ИГИШ использует при обращении к потенциальным рекрутам. Согласно Гартенштейн-Россу, террористическая организация сосредотачивается, главным образом, на следующих трех идеях: религиозный долг, политические обиды и успех Исламского государства. ${ }^{32}$ Независимо от половой принадлежности и возраста, наиболее часто цитируемой причиной для присоединения к ИГИШ является религиозный долг или религиозные убеждения. Многие лица бывают завербованы онлайн. Террористические организации так же используют тюрьмы, религиозные институции и университеты в качестве мест для вербовки. Тюрьмы на Ближнем Востоке стали академиями, в которых ИГИШ вербует и тренирует своих боевиков. ${ }^{33}$ Иностранные боевики, в особенности те, кто проживает вне Исламского государства, наиболее часто бывают завербованы в результате пропаганды посредством онлайн стратегической коммуникации через мессенджеры, социальные медиа и чатрумы. Такие технологии часто используются для вербовки тех, кто вряд ли когда-либо войдет в физический контакт с боевиками ИГИШ. ${ }^{34}$ Согласно Ниссену, главными задачами социальных медиа ИГИШ являются:

- привлечение внимания к посланию о халифате через сайты социальных сетей (ССС). ССС привлекают к ИГИШ международное внимание;

- нахождение финансовой поддержки;

- объединение их сторонников-единомышленников;

- $\quad$ вербовка и обращение новых членов. ${ }^{35}$

Твиттер является главным источником для коммуникационной кампании ИГИШ. Хотя в феврале $2016^{36}$ Твиттер заблокировал 125000 связанных с ИГИШ аккаунтов, ИГИШ всегда успевает обходить «фильтры» и создавать другие твиттер профили. Одним из успешных ССС начинаний ИГИШ является твиттер-приложение Заря радостных вестей или просто Заря. Это приложение на самом деле продукт ИГИШ, пропагандируемый талантливыми пользователями ССС. Его предназначение держать мир в курсе последних деяний или предстоящих действий этой террористической организации. ${ }^{37}$ Другой широко известный аккаунт ИГИШ называется Медиа Исламского

32 Gartenstein-Ross, "Testimony."

33 Weiss and Hassan, ISIS: Inside the Army of Terror.

34 Gartenstein-Ross, "Testimony."

35 Thomas Elkjer Nissen, "Terror.com - IS's Social Media Warfare in Syria and Iraq," Contemporary Conflicts 2, no. 2 (2014): 1-8.

36 Jessica Guynn and Elizabeth Weise, "Twitter Suspends 125,000 ISIL-related Accounts," USA Today, February 5, 2016, c. A1.

37 J.M. Berger, "How ISIS Games Twitter," The Atlantic, June 16, 2014, p. A1. 
государства, в котором организация хвастается истреблением атеистов, женщин-водителей, мусульман-шиитов, курдов и евреев.

Эта организация рассылает серию твиттов с изображениями для распространения посланий и предупреждений. Как многие лица или группы, чей целью является увеличение числа их последователей, они создают «фейковые» аккаунты своих последователей. Это мотивирует реальных сторонников на присоединение к их аккаунтам. ${ }^{38}$ ИГИШ так же использует Фейсбук, Инстаграм, Скайп и Ютюб. Эти СС обычно используются для привлечения к диалогу возможных рекрутов. Устанавливается межличностный диалог с потенциальными мусульманскими братьями и сестрами. Имеется множество онлайн видеороликов, которые распространяют послания ИГИШ, его цели и такие ритуалы, как обезглавливание. Эта террористическая организация публикует и свое собственное издание, Dabiq. Точнее, Dabiq является ежемесячным онлайн журналом (50-60 страниц), который восхваляет достоинства шариата и джихада и отдает почтение мученикам, погибшим на священной войне. ${ }^{39}$ Как объясняет Ниссен, ИГИШ «применяет технологии, которые обычно ассоциируются с политическими кампаниями, например, озвучиванием возможной поддержки через обратную связь относительно потенциальных идей, терминов и графических изображений». ${ }^{40}$ Группировка проводит онлайн «кампанию», распространяя информацию о своем деле и о своей организации через социальные медиа, статьи, видеоматериалы и вебсайты - используются все подходящие инструменты для вербовки людей для участия в борьбе.

\section{Вербовка женщин, осуществляемая ИГИШ}

Особое внимание при вербовке ИГИШ уделяет молодежи по нескольким ключевым причинам. Прежде всего, у молодых рекрутов чистый «послужной список» и они акклиматизированы к западной культуре, что выгодно руководителям, поскольку такие люди привлекают меньше внимания. ${ }^{41}$ Другим преимуществом использования молодых людей является то, что если они будут задержаны властями, они могут получить более легкие наказания из-за своего молодого возраста. Хотя основными объектами вербовки являются молодые мужчины, в последнее время имеет место расширение вербовки женщин. ${ }^{42}$ Женщины обычно подвергаются вербовке в ак-

38 Nissen, "Terror.com -IS's Social Media Warfare in Syria and Iraq."

39 Till F. Paasche and Michael M. Gunter, "Revisiting Western Strategies against the Islamic State in Iraq and Syria," The Middle East Journal 70, no. 1 (2016): 9-29.

40 Nissen, "Terror.com -IS's Social Media Warfare in Syria and Iraq," c. 3.

41 Seong Hun $\mathrm{Yu}$ and Omar Sultan Haque, "Vulnerabilities among Young Westerners Joining ISIS," The Brown University Child and Adolescent Behavior Letter 32, no. 2 (2016): 1-6.

42 Thomas R. McCabe, "A Strategy for the ISIS Foreign Fighter Threat," Orbis 60, no. 1 (2016): 140-153. 
тивных онлайн чатрумах и разных ССС. Это гораздо более удобная платформа для вербовки по сравнению с методами вербовки 1990-х, когда вербовщикам-террористам приходилось в большей степени полагаться на взаимодействие лицом к лицу. ${ }^{43}$

Хотя многие женщины чувствуют себя обязанными присоединиться к ИГИШ по религиозным причинам, имеется также множество женщин, действующих под влиянием личных желаний и потребностей. Как утверждает Шервуд, «некоторым молодым женщинам предлагали финансовые стимулы, например, уплату дорожных расходов или денежные компенсации за рождение детей для ИГИШ». ${ }^{44}$ Таким женщинам обычно обещают признание, сестринство и любовь. Часто с этими рекрутами женского пола беседуют мужчины, которые устанавливают определенные отношения с ними. После вербовки от них ожидают, что они выйдут замуж и будут рожать детей для обеспечения будущего организации». ${ }^{45}$ Наблюдается резкое увеличение числа западных женщин, в основном европейских, уезжающих на Ближний Восток. К сожалению, хотя большинство женщин, подвергшихся вербовке и оказавшихся завербованными, находятся в возрасте от 16 до 24 лет, были выявлены случаи вербовки девушек моложе 13 лет. ${ }^{46}$ Как сформулировал это Томас Самуэль,

Эти группы привлекают молодых людей, используя их уязвимость и давая им ощущение идентичности, принадлежности и привязанности. В течение некоторого периода времени, в неблагополучной среде, эти молодые люди начинают отождествлять свою идентичность с идентичностью группы и с ее борьбой. ${ }^{47}$

\section{Решение для кризиса идентичности молодых людей}

Сегодня определенное число молодых людей - даже те, кто живет в Европе и в Северной Америке - переживают кризис идентичности: они борются с безработицей, с отчаянием и с тем, что они воспринимают как социальное отвержение. ${ }^{48}$ Это делает их особенно подходящими для вербовки со стороны ИГИШ. Молодые люди, живущие в нищете, тоже являются объектом

43 Mia M. Bloom, "In Defense of Honor: Women and Terrorist Recruitment on the Internet," Journal of Postcolonial Cultures and Societies 4, no. 1 (2013): 150-195.

44 Harriet Sherwood, Sandra Laville, Kim Willsher, Ben Knight, Maddy French, and Lauren Gambino, "Schoolgirl Jihadist: The Female Islamists Leaving Home to Join Isis Fighters," The Guardian, September 29, 2014, c. A1.

45 Bloom, "In Defense of Honor: Women and Terrorist Recruitment on the Internet."

46 Sherwood et al., "Schoolgirl Jihadist."

47 Thomas Koruth Samuel, "The Lure of Youth into Terrorism," SEARCCT's Selection of Articles 2 (2011): 107-119, цитата на c. 109, http://www.searcct.gov.my/publications/ our-publications?id=55.

48 Alex S. Wilner and Claire-Jehanne Dubouloz, "Homegrown Terrorism and Transformative Learning: An Interdisciplinary Approach to Understanding Radicalization," Global Change, Peace \& Security 22, no. 1 (2010): 33-51. 
специального внимания ИГИШ. Этим юношам ИГИШ как будто предлагает перспективу, чувство принадлежности и братства, и, конечно, приключения, храбрость и мученичество. Вдохновленный ИГИШ джихад является беспрецедентным заместителем наркотиков и ежедневной преступности и неконвенциональным глобальным движением с ясными и четкими правилами. ${ }^{49}$ Согласно Стерну, после терактов 9/11 значительное число западных молодых людей присоединилось к джихадистскому движению в результате чувства унижения. ${ }^{50}$ Они чувствуют, что Запад возобладал над ними и преднамеренно унижает их, заставляя их взяться за оружие и бороться. Стерн также указывает на то, что для священной войны джихадистским группировкам нужны молодые люди, которые чувствуют себя униженными и в растерянности. ${ }^{51}$ Когда появляются такие впечатлительные рекруты, они в свою очередь становятся лидерами и начинают воспользоваться другими неустойчивыми людьми. Вот как ИГИШ привлекает, вербует людей и обеспечивает их преданность группировке.

\section{Рассмотрение вербовки, осуществляемой ИГИШ, через призму теории развития отношений}

Для анализа процесса вербовки ИГИШ людей по всему миру используется теория развития отношений. Точнее, этот анализ находит корреляцию между пятью этапами эскалации отношений и усилиями, которые ИГИш прикладывает для обеспечения поддержки и привлечения сторонников. Мы анализируем каждый этап, описанный в теории, и соотносим его с методами, которые ИГИШ использует для коммуникации с людьми по всему миру при осуществлении своей пропаганды и обеспечения себе поддержки. Важно отметить, что такая модель вербовки ИГИШ имеет место не только на Ближнем Востоке, но и в Западном мире. ${ }^{52}$

\section{Инициация}

Предположительно инициация является наиболее важным этапом: коммуникационный аспект вербовки только начинается. Вербовщик или единомышленник устанавливает контакт с лицом или с возможным рекрутом. На этом этапе люди признают друг друга и начинают делиться своими дискурсами. Сегодня стало скорее обычным инициировать дискурсы онлайн через

49 Rik Coolsaet, What Drives Europeans to Syria, and to IS? Insights from the Belgian Case (Brussels: Royal Institute for International Relations, 2015), http://www.egmontinstitute.be/what-drives-europeans-to-syria-and-to-is-insightsfrom-the-belgian-case/.

50 Jessica Stern, "Militant Groups: Beneath Bombast and Bombs, a Cauldron of Humiliation," Los Angeles Times, June 6, 2004, c. A1.

51 Stern, "Militant Groups: Beneath Bombast and Bombs."

52 Xu Zhang and Lea Hellmueller, "Transnational Media Coverage of the ISIS Threat: A Global Perspective?" International Journal of Communication 10 (2016): 766-785. 
ССС, чем лично лицом к лицу. Используя онлайн чатрумы, Фейсбук и Твиттер, ИГИШ поддерживает вебсайты и журналы, которые играют роль создания положительного «первого впечатления».

Dabiq, издаваемый ИГИШ журнал, оказывается в состоянии произвести положительное «первое впечатление», желаемое ИГИШ. Этот ежемесячный журнал хорошо сверстан и нацелен на западную молодежь. На самом деле, статьи в нем написаны на совершенном английском, они содержат множество хороших, цветных изображений и показывают славно выглядевших боевиков на джипах Тойота. 53 Через Dabiq и разные ССС ИГИШ использует Всемирную сеть и глубокую сеть, - когда содержание во Всемирной сети не может быть легко найдено при использовании стандартных поисковиков $^{54}$ - для пропаганды джихада, прославления халифата и обещания награды от аллаха (т.е. в загробной жизни с девами и слугами, а также мирные пейзажи с водопадами и разгуливающими львами в их видеороликах). ${ }^{55}$ На этапе инициации этот первый контакт может быть также инициирован любопытным онлайн потребителем; в этом случае человек контактирует с лицом, о котором он думает, что оно связано с ИГИШ. Для тех потребителей, которые зарегистрировались на связанными с ИГИШ ССС, твитты ИГИШ содержат ссылки, хэштеги и изображения. То же содержание часто распространяется как твиты через твиттер аккаунты других потребителей. ${ }^{56}$

В материале для The Times of India Хафиз рассказывает, как Ариф Маджид, которому в 2014 году было 23 года, инициировал контакт с вербовщиком ИГИШ в интернет чатруме. ${ }^{57}$ Далее Хафиз рассказывает, что Ариф Маджид «сказал людям, которые его допрашивали, что его индоктринация началась после посещения интернет чатрума. Его убедили стать членом террористической группировки и ему дали телефонный номер лица, чьи люди подобрали его из Мосула в Ираке». ${ }^{58}$ Впечатлительные молодые люди часто используют ССС или чатрумы, чтобы начать коммуникацию. Поэтому, чем лучше первое впечатление, произведенное вербовщиком, тем больше число возможных будущих братьев и сестер по ИГИШ. Чтобы иметь успех, у вербовщика должна быть харизма.

53 Matthew Mosk, Brian Ross, and Alex Hosenball, "US Officials Ask How ISIS Got So Many Toyota Trucks," ABC News, October 6, 2015, https://abcnews.go.com/ International/us-officials-isis-toyota-trucks/story?id=34266539 (April 6, 2017).

54 Mhamed Zineddine, "Search Engines Crawling Process Optimization: A Webserver Approach," Internet Research 26, no. 1 (2016): 311-331.

55 Harry E. Wedeck and Wade Baskin, Dictionary of Pagan Religions (New York: Philosophical Library, 2015).

56 Berger, "How ISIS Games Twitter."

57 Mateen Hafeez, "Radicalized on Net Chat Room, Given Mosul Contact: ISIS Man," The Times of India, November 30, 2014, c. A1.

58 Hafeez, "Radicalized on Net Chat Room," c. A1. 


\section{Экспериментирование}

Экспериментирование является второй фазой. Этот этап начинается после того, как вербовщик произвел первое впечатление, и взаимодействующие субъекты решают продолжить коммуникацию. После того, как был установлен контакт с вербовщиком, потенциальный рекрут хочет узнать больше об идее. Часто задается множество вопросов (обеими сторонами) во время онлайн чатов или посредством ССС постов. Как это было в случае Арифа Маджида, потенциальный рекрут может задавать вопросы об образе жизни в ИГИШ или что означает готовиться и умереть во имя аллаха. ${ }^{59}$ Этот этап состоит, в основном, из общих разговоров. Что касается вышеупомянутого твиттер приложения, которое создало ИГИШ - Заря радостных вестей или просто Заря - на него могут зарегистрироваться бесконечное число потребителей (в интернете или на своих смартфонах). Когда потребитель скачивает это приложение, ИГИШ незамедлительно задает некоторые персональные вопросы. ${ }^{60}$ Это и есть прямое воплощение этапа экспериментирования.

На этом этапе сбора информации вербовщики ИГИШ рисуют живописную картину джихадисткого дела и всего, что оно может предложить. Они говорят потенциальным рекрутам все, что те хотят услышать для того, чтобы привлечь их внимание и добиться их поддержки. К примеру, вербовщик создает положительную атмосферу в ходе межличностного диалога, преувеличивая славу и доброжелательный прием, с которыми будет встречен рекрут после вступления в ряды ИГИШ (из-за своей преданности аллаху). Они так же могут повышать положительный настрой обещая любви, братства и соответствующего вознаграждения. Dabiq четко описывает астрономическое материальное богатство ИГИШ: в дополнение к строительству пятизвездочных отелей в Мосуле, организация дает зарплату и виллу с бассейном преданным моджахедам. И не на последнем месте, Dabiq рассказывает, как ИГИШ дает возможность новым рекрутам применять власть над другими вплоть до упражнения садизма во имя аллаха. ${ }^{61}$

На этапе экспериментирования люди решают, будут ли они развивать дальше данные отношения, продолжать или нет. Согласно Дрисколлу, с одной женщиной, которая вступила в онлайн коммуникацию под прикрытием, вошел в контакт боевик ИГИШ, чьей целью было завербовать ее. Он постоянно осыпал ее комплиментами и обещал ей, что «когда она будет там, к ней будут относиться, как к принцессе». ${ }^{62}$ Прививая такие идеи в со-

59 Hafeez, "Radicalized on Net Chat Room."

60 Berger, "How ISIS Games Twitter."

61 Heather Saul, "ISIS Opens 262-room Luxury Hotel in Mosul," Independent, May 6, 2015, c. A1.

62 Margarette Driscoll, “My ISIS Boyfriend: A Reporter's Undercover Life with a Terrorist," New York Post, March 7, 2015, c. A1. 
знание потенциальных новых рекрутов, радикализатор ИГИШ может рисовать райскую жизнь для успешных мучеников, и в результате этого легко оказать влияние на них для перехода к следующему этапу. Они не только рекламируют идеальную жизнь; они рисуют загробную жизнь как блаженство в Джанна (небесных садах). ${ }^{63}$

\section{Интенсификация}

На протяжении этапа интенсификации вербовщики ИГИШ уже закрепили контакт с потенциальными рекрутами через ССС или чатрум. Иначе говоря, ИГИШ уже установило комфортабельный диалог, в ходе которого они начинают формировать что-то вроде долгосрочной связи. На этом этапе другим типичным инструментом большого значения является Скайп, поскольку вовлеченные в контакт люди хотят выразить себя визуально; это показывает, что они перешли в фазу, когда они чувствуют себя более свободно и начинают делиться такой персональной информацией, как обидные для них переживания. ${ }^{64}$ Таким примером является случай Абдельазиза Кувана, подростка из Бахрейна, который принял решение присоединиться к ИГИШ в 2014 году после того, как в течение нескольких месяцев общался через Скайп с «некоторыми из братьев» в Сирии. ${ }^{65}$ Эта история показывает еще, что взаимодействующие субъекты уже не ведут общих разговоров, но становятся более серьезными. ИГИШ скармливает людям фальшивые обещания для того, чтобы пропагандировать положительный образ. Вербовщики пользуются неуверенностью и нуждами людей, используют раскрытую информацию для манипулирования личности.

На данном этапе вербовщики ИГИШ настоятельно убеждают человека присоединиться к их организации, и отношения по своему характеру становятся более близкими. Абдельазизу было предложено отправиться в Сирию для того, чтобы включиться в борьбу. Ему удалось убедить свою мать дать ему его паспорт. ${ }^{66}$ На этом этапе женщины склонны вступать в онлайн отношения «романтического типа» с членом ИГИШ - феномен, называемый «любовный джихад", ${ }^{67}$ - что облегчает переход к последним двум этапам: этапам интегрирования и привязывания. В то же время вербовщики избегают обсуждения ужасов и потенциальных рисков, с которыми сталкиваются многие, решившие вступить в ИГИШ. Большинство женщин бывают привлечены разговорами о теплом приеме, любви и признании. Однако,

63 Jonathan Matusitz, Symbolism in Terrorism: Motivation, Communication, and Behavior (Lanham, MD: Rowman \& Littlefield, 2014).

64 Joshua R. Pederson and Rachel M. McLaren, "Managing Information Following Hurtful Experiences: How Personal Network Members Negotiate Private Information," Journal of Social and Personal Relationships 33, no. 7 (2015): 961-983.

65 Weiss and Hassan, ISIS: Inside the Army of Terror.

66 Pederson and McLaren, "Managing Information Following Hurtful Experiences."

67 Kishalaya Mukhopadhay, "Queering the Narrative: Can the Subaltern Sex Speak?" Economic \& Political Weekly 51, no. 2 (2016): 20-23. 
как и большинство рекрутов, они остаются в неведении о своих действительных правах, условиях проживания и отсутствия свободы, с которыми они столкнутся по прибытии в Сирию или Ирак. ${ }^{68}$ Этап интенсификации имеет большое значение для процесса вербовки, поскольку он позволяет вербовщикам ИГИШ заставить людей поверить, что их заботы исчезнут, как только они вступят в организацию.

После изучения множества статей об этих вербовщиках ИГИШ, стало очевидным, что многие методы вербовки ИГИШ используют аналогичные схемы ответов и игнорирования любых негативных моментов (заменяя негативные тревоги позитивным стимулированием). Вербовщики ИГИШ используют поощрение для того, чтобы убедить рекрута - например, произнося краткие и простые, но убедительные фразы типа «Многие люди ежедневно отправляются в эту поездку», «Не в первый раз страны объединяются против верующих», «Идите в Шам (Сирию) потому, что это лучшая страна аллаха на земле», и "Нужно жить в халифате». ${ }^{69}$ Вербовщики даже убеждали любопытных онлайн потребителей вступать в разговор со своими близкими, чтобы прощупать их мнение и попытаться завербовать их поехать вместе с ними. В других случаях, вербовщики успевали убедить молодых людей скрыться и таким образом избежать выявления и ареста. В частности, риску подвергались молодые женщины на Западе. Таким был случай с тремя девушками, которые исчезли из Объединенного Королевства и были обнаружены в Турции на пути к Сирийской границе. Их убедили присоединиться к делу ИГИШ в результате онлайн взаимодействия с вербовщиками ИГИШ в течение нескольких месяцев. ${ }^{70}$

\section{Интегрирование}

В этом контексте интегрирование является само по себе успешной вербовкой, так как новые рекруты отправляются в Сирию или Ирак для вступления в ИГИШ. Однажды завербованные, люди начинают воспринимать себя как часть джихадистского дела. Посредством множества взаимодействий с ИГИШ на месте, они начинают воспринимать себя как «мы» и ассоциируют себя с террористической группировкой. В среде ИГИШ интегрирование означает ориентация «мы против них». Как вербальное, так и физическое взаимодействие на этом этапе становится более интимным. Новые рекруты переходят от состояния отдельных личностей к состоянию членов ИГИШ процесс, называемый де-плюрализацией. ${ }^{71}$ Де-плюрализация является

68 Zainab Salbi, "Rape Survivor Who Escaped ISIS Discusses Torture She Was Subjected to," The New York Times, June 23, 2015, c. A1.

69 Tom Whitehead, "Secret Cell of British Muslim Women Encouraging Others to Join Islamic State Exposed," The Telegraph, November 23, 2015, c. A1.

70 Josh Halliday, Aisha Gani, and Vikram Dodd, "UK Police Launch Hunt for London Schoolgirls Feared to Have Fled to Syria," The Guardian, February 20, 2015, c. A1.

71 Margaret Singer with Janja Lalich, Cults in Our Midst: The Hidden Menace in Our Everyday Lives (San Francisco: Jossey-Bass, 1995). 
процессом, при котором данная личность отказывается от своего старого «я», чтобы принять новое «я». По существу, присоединение к ИГИШ требует интегрирования нового, связанного с группой «я», путем принятия философии целой группы и смешивания с другими членами. ${ }^{72}$ В процессе интегрирования, вербовщик активно планирует миссию и место новых рекрутов в рамках элитарного мусульманского братства.

\section{Привязывание}

Последним этапом эскалации отношений является привязывание, при котором формируются близкие отношения и люди становятся полностью преданными борьбе ИГИШ и дают клятву на верность Абу-Бакр аль-Багдади, текущему лидеру ИГИШ. ${ }^{73}$ Теперь рекруты ИГИШ являются полноценными членами террористической организации. Важным аспектом этой фазы является то, что люди теперь идентифицируют себя с ИГИШ публично. Они загружают видеоклипы своего нового Я в ИГИШ или распространяют твиты о своей джихадистской жизни через ССС. ${ }^{74}$ Члены имеют символические знаки, которые они используют, чтобы показать свою поддержку, например, стоят с поднятым вверх указательным пальцем, выражая солидарность с бойцами халифата. По существу, эти невербальные жесты символизируют связь между ИГИШ и аллахом, отражая следующее послание: мы призваны аллахом, чтобы убивать каждого, пока не будет создан халифат. ${ }^{75}$

Чтобы доказать свою полную преданность ИГИШ, новые члены должны быть "допущены» в группу через ритуал публичной инициации. Точнее, они должны принять участие в публичной акции убийства врага - даже если это означало бы убить свою собственную мать. В феврале 2016 года молодой рекрут ИГИШ убил свою собственную мать, которая не поддерживала дело ИгИШ. Ее обвинили в вероотступничестве после того, как ее сын донес на нее старшим членам ИГИШ. Сына женщины, двадцатилетнего Аки Сакр аль Касем, убедили казнить ее своими собственными руками. После демонстрации своей смертельной преданности, его верность ИГИШ была вне сомнения, и этапу привязывания была поставлена точка. ${ }^{76}$ На этапе привязывания эти полноправные члены ИГИШ начинают пытаться оказывать влияние на других, чтобы они присоединились к ним и даже сами могут стать вербовщиками. С другой стороны, очень маловероятно, что среднестати-

72 Barbara Franz, "Popjihadism: Why Young European Muslims Are Joining the Islamic State," Mediterranean Quarterly 26, no. 2 (2015): 5-20.

73 McCabe, "A Strategy for the ISIS Foreign Fighter Threat."

74 Diana Secara, "The Role of Social Networks in the Work of Terrorist Groups. The Case of ISIS and Al-Qaeda," Research and Science Today, Summlement 3 (2015): 77-83.

75 Orlando Crowcroft, "ISIS: What is the Story Behind the Islamic State One-fingered Salute?" International Business Times, June 15, 2015, c. A1.

76 John Hall, "ISIS Militant Ali Saqr al-Qasem Publicly Executes Own Mother in Raqqa after Accusing Her of 'Apostasy'," Independent, January 8, 2016, c. A1. 
стический член ИГИШ отойдет от дела. Этот финальный этап завершает процесс вербовки и в результате появляется новый сторонник и боевик для Исламского государства.

\section{Дискуссия и рекомендации на будущее}

Этот анализ показал, что ИГИШ может успешно вербовать множество людей по всему свету - особенно молодых мужчин и женщин - благодаря поэтапному развитию отношений через интернет чатрумы и такие сайты социальных сетей (ССС), как Твиттер. Также мы считаем, что если бы ИГИШ не использовало интернет чатрумы и ССС и, если бы ИГИШ не следовало бы этим этапам эскалации отношений, их процесс вербовки не был бы столь эффективным. С этой точки зрения, пять этапов эскалации отношений позволяют нам увидеть как формируются отношения и дают нам возможность понять всю сложность межличностных взаимодействий (как офлайн, так и онлайн).

В общем и целом, изучая вербовку, проводимую ИГИШ, мы наблюдаем тенденцию позитивных уверений, даваемых вербовщиками террористов, с целью убедить отдельных людей присоединиться к делу джихадистов. Согласно Матусицу, «одним из методов разрешения кризиса отношений является или усиление положительных чувств или ослабление отрицательных с тем, чтобы обеспечить комфорт другой стороны в ходе диалога». ${ }^{77}$ Усиливая позитивные моменты, ИГИШ может дать возможность рекруту почувствовать себя комфортабельно и сделать его подверженным манипулированию. Целью ИГИШ является уничтожение неверующих и создание всемирного халифата. Поэтому на каждом этапе вербовки в качестве формы убеждения используются позитивизм и поощрение. Эта террористическая организация доказала, что отлично владеет этим процессом. Важно, чтобы мы понимали, как ИГИШ использует эти этапы, чтобы мы могли лучше помогать жертвам и положить конец широкомасштабной вербовке.

В будущих исследованиях было бы интересно рассмотреть два дополнительных аспекта вербовки, осуществляемой ИГИШ. Во-первых, при текущем миграционном кризисе, при котором более миллиона соискателей на убежище бежали из таких мусульманских стран, как Сирия, Ирак и Афганистан, а также из раздираемых войной странах Африки, ${ }^{78}$ будет ли ИГИШ более успешным в вербовке будущих джихадистов, проникая в лагеря беженцев? Британский премьер-министр Дэвид Кэмерон предостерег нас, что «один из каждых пятидесяти беженцев в Европе может быть джихадистом ИГИШ». ${ }^{79}$ В этих обстоятельствах было бы полезно сравнить нынешнюю вербовку, проводимую ИГИШ через ССС, с проникновением в лагеря беженцев.

77 Matusitz, Terrorism and Communication: A Critical Introduction, цитата на с. 365.

78 Tim Arango, "Disappointed with Europe, Thousands of Iraqi Migrants Return Home," The New York Times, February 4, 2016, c. A1.

79 Cited in Alexandra Sims, " 1 in 50 Syrian Refugees in Europe Could be an ISIS Jihadist, Minister Warns David Cameron," Independent, September 15, 2015, c. A1. 
Задачей данного сравнения было бы определить, которая из этих двух технологиях является более эффективной.

Во-вторых, надвигается один важный вопрос: хотя исследования и статьи подтвердили, что большое число онлайн рекрутов ИГИШ являются молодыми мужчинами и женщинами, могут ли все они быть настолько наивными, одинокими и недовольными? Верно, что надо учитывать множество вещей, чтобы произвести хорошее первое впечатление - от харизматической коммуникации до привлекательных видеорядов и языка тела. Тем не менее, широко известно, что определенное число молодых членов ИГИШ являются высоко образованными личностями с университетскими степенями и углубленным знанием науки и инжиниринга. ${ }^{80}$ Поэтому, какие другие факторы мотивируют молодых присоединяться к ИГИШ? Ответ на эти вопросы надо найти в результате серьезных исследований.

Авторы надеются, что этот анализ вербовки, проводимой ИГИШ с использованием теории развития отношений, пролил для читателей свет на то, как эффективные онлайн социальные медиа может способствовать успешной вербовке, осуществляемой террористической организацией. Этот анализ может помочь другим понять, насколько легко может быть манипулировать людьми и убедить их присоединиться к террористической группировке, просто используя ССС. Теория развития отношений была применена к предмету, который прежде не был исследован с такой теоретической точки зрения, что является положительным вкладом в теорию коммуникаций в целом. Теперь и теоретики, и практики могут рассматривать процесс вербовки, осуществляемой ИГИШ, под другим углом.

\section{Об авторах}

Сара Пондер является младшим научным сотрудником Школы коммуникаций им. Никольсона при Университете Центральной Флориды. В число ее академических интересов входят исследования по вопросам терроризма, конфликтов и межкультурных коммуникаций.

Джонатан Матусиц, кандидат наук, доцент Школы коммуникаций им. Никольсона при Университете Центральной Флориды. В число его академических интересов входят исследования по вопросам терроризма, коммуникаций и технологий и межкультурных коммуникаций. Пожалуйста, направляйте корреспонденцию для Джонатана Матусица по адресу: University of Central Florida at Seminole State College, Partnership Center (\#UP 3009), 100

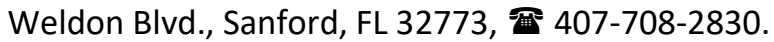

E-mail: matusitz@gmail.com.

80 Maajid Nawaz, "The Education of “Jihadi John," The New York Times, March 3, 2015, c. A1. 